University of Nebraska - Lincoln

DigitalCommons@University of Nebraska - Lincoln

Faculty Publications in Food Science and Technology

2019

Extraction of astaxanthin from engineered Camelina sativa seed using ethanol-modified supercritical carbon dioxide

Liyang Xie

Edgar B. Cahoon

Yue Zhang

Ozan Ciftci

Follow this and additional works at: https://digitalcommons.unl.edu/foodsciefacpub

Part of the Chemical Engineering Commons, and the Food Science Commons

This Article is brought to you for free and open access by the Food Science and Technology Department at DigitalCommons@University of Nebraska - Lincoln. It has been accepted for inclusion in Faculty Publications in Food Science and Technology by an authorized administrator of DigitalCommons@University of Nebraska Lincoln. 


\title{
Extraction of astaxanthin from engineered Camelina sativa seed using ethanol-modified supercritical carbon dioxide
}

\author{
Liyang Xie, ${ }^{1}$ Edgar Cahoon, ${ }^{2}$ Yue Zhang, ${ }_{1}^{1} \&$ Ozan N. Ciftci ${ }^{1}$
}

1 Department of Food Science and Technology, University of Nebraska-Lincoln, Lincoln, NE 68588-6205, USA

2 Center for Plant Science Innovation and Department of Biochemistry, University of Nebraska-Lincoln, Lincoln, NE 68588, USA

Corresponding author — O.N. Ciftci, email ciftci@unl.edu

\begin{abstract}
Natural astaxanthin, a high-value carotenoid that is currently extracted mainly from marine organisms, was extracted from engineered camelina seed using ethanolmodified supercritical carbon dioxide $\left(\mathrm{SC}-\mathrm{CO}_{2}\right)$ for the first time, and compared with hexane and accelerated solvent extraction using hexane and ethanol. Response surface methodology (RSM) based on central composite rotatable design was employed to investigate the effect of pressure $(30-45 \mathrm{MPa})$, temperature $\left(40-60{ }^{\circ} \mathrm{C}\right)$, and ethanol concentration (10-35\%, w/w). RSM-optimized conditions (41.6 MPa, $36.6^{\circ} \mathrm{C}$ and $42.0 \%$ ethanol concentration) predicted the astaxanthin concentration as $437 \mu \mathrm{g} / \mathrm{g}$ oil, whereas the actual concentration was $421 \pm 14 \mu \mathrm{g} / \mathrm{g}$ oil. Astaxanthin concentration in accelerated solvent extracted oil was significantly lower than that in ethanol-modified $\mathrm{SC}_{-} \mathrm{CO}_{2}$ - and hexane-extracted oils $(\mathrm{P}<0.05)$. Oils extracted with ethanol-modified SC-CO2 had the highest antioxidant activity. Results indicated that ethanol-modified $\mathrm{SC}-\mathrm{CO}_{2}$ extraction method can be successfully used as a green method to extract astaxanthin from high oil feedstocks.
\end{abstract}

Keywords: Astaxanthin, Supercritical carbon dioxide, Extraction, Camelina seed

Published in The Journal of Supercritical Fluids 143 (2019), pp 171-178.

doi: 10.1016/j.supflu.2018.08.013

Copyright (c) 2018 Elsevier B.V. Used by permission.

Submitted 27 June 2018; revised 17 August 2018; accepted 19 August 2018; published

20 August 2018. 


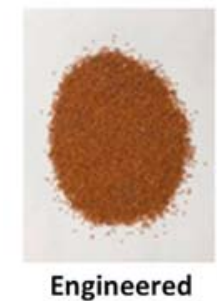

astaxanthin-rich camelina seed

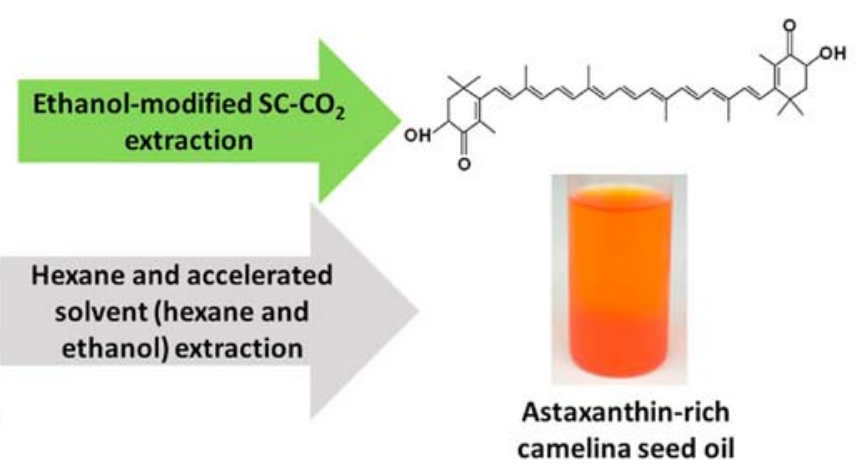

\section{Introduction}

Astaxanthin (3,3,-dihydroxy- $\beta$-carotene-4,4,-dione) is a red color fatsoluble pigment which belongs to the keto-carotenoid family. It has been reported that astaxanthin's antioxidant activity is ten times higher than other carotenoids such as beta-carotene and lutein, and over 500 hundred times higher than tocopherol [1]. Growing evidence also shows that astaxanthin provides beneficial effects on human health, including the enhancement of general well-being and immune system, protection against lipid membrane peroxidation and DNA damage, gastrointestinal cancers, degenerative ailments such as Parkinson's and Alzheimer's diseases; chronic inflammatory diseases; metabolic disorders such as diabetes; and cardiovascular diseases $[2,3]$.

Astaxanthin is the highest value carotenoid that is currently used in the food, feed, nutraceutical and pharmaceutical industries. Currently, more than $95 \%$ of the astaxanthin used in aquaculture is synthesized artificially [2]. There is an increasing demand for the natural astaxanthin due to growing demand for natural ingredients. Currently, the most popular source of natural astaxanthin is microalgae Haematococcus pluvialis. Various microorganisms such as green algae Haematococcus pluvialis and Chlorella zofingiensis, red yeast Phaffia rhodozyma and marine bacterium Agrobacterium aurantiacum can produce astaxanthin [4]. Other natural sources of astaxanthin include wild $\mathrm{Pa}$ cific sockeye salmon, lobster, arctic shrimp, crab, crawfish, red trout, algae, and krill. However, the potential of current sources is limited and is not sufficient to supply the global astaxanthin market [5]. 
In recent years, there have been some attempts to synthesize astaxanthin in carrot [6], tomato [7], and corn [5] through metabolic engineering. However, the engineered plants make the development of new extraction methods crucial as current methods are based on marine organisms, which are high water content materials. Camelina seed contains high amount of oil (€40\%) and its water content is much lower than that of current natural astaxanthin sources, which in turn affect the selection of the solvent and extraction method and conditions for efficient recovery of astaxanthin from the source.

Astaxanthin is sensitive to light and oxygen; therefore, may degrade during extraction. Moreover, there is a growing demand for clean extraction methods by consumers and manufacturers for labeling and marketing purposes. Supercritical carbon dioxide (SC$\mathrm{CO}_{2}$ ) has been used as an alternative clean extraction method for various oilseeds such as flaxseed [8], sunflower seed [9] and watermelon seed [10] and various lipid compounds such as lycopene from tomato seeds [11] and lutein from spinach [12]. Pure SC- $\mathrm{CO}_{2}$ is nonpolar; therefore, it extracts nonpolar compounds. Because astaxanthin is slightly polar, the polarity of $\mathrm{SC}-\mathrm{CO}_{2}$ was improved by modifying ethanol, which is a food grade solvent, to extract astaxanthin from Haematococcus pluvialis [13], Brazilian redspotted shrimp waste [14] and tiger shrimp [15].

There is no reported study on the extraction of astaxanthin from an oilseed using $\mathrm{SC}-\mathrm{CO}_{2}$ or ethanol-modified $\mathrm{SC}-\mathrm{CO}_{2}$. In this study, engineered camelina seed was used for the first time as an alternative nonmarine astaxanthin source. The main objective of this study was to investigate the feasibility of ethanol-modified $\mathrm{SC}-\mathrm{CO}_{2}$ extraction of astaxanthin from engineered camelina seed. The specific objectives were: (i) to study the effects of ethanol modified-SC- $\mathrm{CO}_{2}$ extraction parameters, namely, pressure, temperature and ethanol concentration on the extraction of astaxanthin using response surface methodology (RSM); (ii) to optimize the ethanol-modified SC$\mathrm{CO}_{2}$ extraction conditions using RSM; (iii) to compare the $\mathrm{SC}-\mathrm{CO}_{2}$, opt extraction with conventional hexane extraction and accelerated ethanol and hexane extractions in terms of oil yield and astaxanthin concentrations of the extracted oils; and iv) to evaluate the effect of the extraction method on the antioxidant activity of the astaxanthin-rich camelina seed oils. 


\section{Materials and methods}

\subsection{Materials}

Astaxanthin-enriched camelina seeds were provided by the Plant Innovation Center at the University of Nebraska-Lincoln. Seeds were ground using an analytical mill (A11 basic, IKA Works, Inc., Wilmington, NC, USA) and sieved to obtain the particles smaller than $0.3 \mathrm{~mm}$. $\mathrm{CO}_{2}$ (99.99\% purity) was purchased from Matheson (Lincoln, NE, USA). Astaxanthin from Haematococcus pluvialis ( $\geq 97 \%$ purity) and trans- $\beta$ apo-8'-carotenal ( $\geq 96 \%$ purity) standards were purchased from Sigma Aldrich (St Louis, MO, USA). Rac-5,7-Dimethyltocol was purchased from Matreya LLC. (State College, PA, USA). All other reagents and solvents were of analytical or chromatographic grade.

\subsection{Ethanol-modified $\mathrm{SC}-\mathrm{CO}_{2}$ extraction}

Ethanol-modified $\mathrm{SC}-\mathrm{CO}_{2}$ extractions were carried out in a laboratory scale SC-CO 2 extraction system (SFT 110, Supercritical Fluids, Inc., Newark, DE, USA). Schematic diagram of the system was reported previously [16]. For each experiment, the extraction vessel was loaded with $10 \mathrm{~g}$ of ground camelina seed. The air in the vessel was flushed out by opening the $\mathrm{CO}_{2}$ cylinder before each run for $2 \mathrm{~min}$. Then, the shutoff valve was closed, and the extraction vessel heated to the extraction temperature in the oven of the system. After reaching the set extraction temperature, $\mathrm{CO}_{2}$ was pumped into the system using the high-pressure $\mathrm{CO}_{2}$ pump, and ethanol was pumped into the system at an inlet point before the extraction vessel using the co-solvent pump at the predetermined flow rates to attain the set ethanol concentrations. Extraction pressure was monitored and maintained constant using the $\mathrm{CO}_{2}$ pump. A static extraction time of 20 min was established by keeping the shut-off valve closed. Then, the shut-off valve was opened, and the extracted oil was collected continuously in an amber glass sample collection vial held in a cold trap at $-10^{\circ} \mathrm{C}$. $\mathrm{CO}_{2}$ flow rate was maintained at $1 \mathrm{~L} / \mathrm{min}$ (measured at ambient conditions) with a heated micrometering valve, and measured by the gas flow meter placed after the sample collection vial. The ethanol in the extracted oils was evaporated under nitrogen flow at $40^{\circ} \mathrm{C}$. The amount of oil extracted was determined gravimetrically and the oil 
yield $(\%, w / w)$ was obtained by dividing the mass of oil extracted by the mass of camelina seed used for extraction. The headspace of the vials containing the extracted oil were filled with nitrogen and stored at $-20{ }^{\circ} \mathrm{C}$ until analyzed for astaxanthin concentration.

\subsubsection{Experimental design}

RSM based on a central composition rotatable design (CCRD) with three variables at three levels were used to investigate the effects of extraction variables (pressure, temperature, and ethanol concentration) on the astaxanthin concentration of the extracted oils. Extraction time was limited to $180 \mathrm{~min}$. The three different levels of the three variables were represented in codes as $-1,0$, and +1 . Two extreme levels were coded as -1.68 and +1.68 . The actual levels of the coded and uncoded variables generated by the Design Expert software (Stat-Ease Inc., Minneapolis, MN, USA) were shown in Table 1. The total number of experiments was $20\left(2^{k}+2 k+6\right)$, where $k$ is the number of independent variables. In order to determine the pure error, five replications were performed at the center point. The levels of the variables were determined based on the capabilities of the $\mathrm{SC}-\mathrm{CO}_{2}$ extraction system and the preliminary study.

\subsection{Hexane (Soxhlet) extraction}

Ground camelina seeds (12 g) were extracted with hexane $(250 \mathrm{~mL})$ in a Soxhlet apparatus for $6 \mathrm{~h}$ in dark to prevent photooxidation of astaxanthin. Hexane was separated from the oil using a rotary vacuum evaporator (Buchi Labortechnik AG, model B-490, Flawil, Switzerland) at $22^{\circ} \mathrm{C}$ after each extraction. The resulting oil was weighed, and the total oil yield was reported as (weight of oil/weight of ground seed

Table 1. Independent variables and levels used for central composite rotatable design (CCRD).

\begin{tabular}{lcccccc} 
& & \multicolumn{5}{c}{ Levels } \\
\cline { 3 - 7 } Variable & $\begin{array}{c}\text { Symbol } \\
\text { coded }\end{array}$ & -1.68 & -1 & 0 & +1 & +1.68 \\
\hline Pressure $(\mathrm{MPa})$ & $\mathrm{X}_{1}$ & 24.9 & 30.0 & 37.5 & 45.0 & 50.1 \\
Temperature $\left({ }^{\circ} \mathrm{C}\right)$ & $\mathrm{X}_{2}$ & 33.2 & 40.0 & 50.0 & 60.0 & 66.8 \\
Ethanol concentration (\%) & $\mathrm{X}_{3}$ & 1.5 & 10.0 & 22.5 & 35.0 & 43.5 \\
\hline
\end{tabular}


used for extraction) $\times 100$. The oil extracts were flushed with nitrogen and stored at $-20^{\circ} \mathrm{C}$ until analyzed for astaxanthin concentration.

\subsection{Accelerated solvent extraction}

Accelerated solvent extractions (ASE) using hexane and ethanol were performed using an accelerated solvent extractor (Dionex ASE 350, Sunnyvale, CA, USA) according to Zaghdoui et al. [17] with minor modifications. Ground camelina seed ( $3 \mathrm{~g}$ ) was mixed with diatomaceous earth (1:3) to reduce the dead volume and then loaded into the $34 \mathrm{~mL}$-extraction cell. Extractions were performed at 1500 psi (10.3 $\mathrm{MPa}$ ) and $40{ }^{\circ} \mathrm{C}$ for 5 static cycles of $5 \mathrm{~min}$. The cell was rinsed with the extraction solvent and the solvent was purged from the cell with nitrogen for $60 \mathrm{~s}$. The solvent in the extract was evaporated under the nitrogen, and the oils were stored at $-20{ }^{\circ} \mathrm{C}$ until analyzed for astaxanthin concentration.

\subsection{Analysis of astaxanthin}

Astaxanthin concentration of the oil samples were determined by a reversed phase high performance liquid chromatography (RP-HPLC) according to Du et al. [18] with minor modifications. The samples were dissolved in acetone $(70 \mathrm{mg} / \mathrm{mL})$ and $15 \mu \mathrm{L}$ of trans- $\beta$-Apo- 8 'carotenal (internal standard) solution ( $1 \mathrm{mg} / \mathrm{mL}$ in acetone) was added to each sample. An aliquot $(10 \mu \mathrm{L})$ was injected into an HPLC (Agilent 1100, Agilent Technologies, Waldbronn, Germany) equipped with a diode array detector (DAD). Samples were separated on a C18 column $(150 \times 4.6 \mathrm{~mm} ; 5 \mu \mathrm{m}$ particle size; Phenomenex Inc., Torrance, CA, USA) using a mobile phase of methanol: acetonitrile $(3: 97, v / v)$ at a flow rate of $1 \mathrm{~mL} / \mathrm{min}$. The column temperature was set at $30^{\circ} \mathrm{C}$ and the elution was detected at $474 \mathrm{~nm}$.

\subsection{Tocopherol analysis}

Tocopherols were analyzed according to the method of Belayneh et al. [19] with minor modification. Ten $\mathrm{mg}$ of each extract was dissolved in $1 \mathrm{~mL}$ methanol: dichloromethane $(9: 1, \mathrm{v} / \mathrm{v})$ solvent mixture and 20 $\mu \mathrm{L}$ of rac-5,7-Dimethyltocol (internal standard) solution $(0.05 \mathrm{mg} / \mathrm{mL})$ was added onto each sample. Then the samples were analyzed by a 
high performance liquid chromatography (HPLC) (1200 Series, Agilent Technologies, Inc., Santa Clara, CA, USA) equipped with a fluorescence detector set at an excitation wavelength of $292 \mathrm{~nm}$ and an emission wavelength of $330 \mathrm{~nm}$. An aliquot $(70 \mu \mathrm{L})$ of prepared solution was separated on a reversed-phase Eclipse XDB-C18 column $(150 \times 4.6 \mathrm{~mm} ; 5 \mu \mathrm{m}$ particle size; Agilent Technologies, Inc., Santa Clara, CA, USA) using a mobile phase of methanol: water (95:5, v/v) at a flow rate of $1.5 \mathrm{~mL} / \mathrm{min}$. Retention time of tocopherol standards was used for identification. Tocopherol content was expressed as the sum of all tocopherols in $\mathrm{mg}$ tocopherol per $\mathrm{kg}$ oil.

\subsection{Measurement of antioxidant activity}

The antioxidant capacity of the oils obtained by different extraction methods was measured by ABTS ${ }^{*}$ radical cation. The ABTS ${ }^{+}$radical cation was generated by reacting $7 \mathrm{mmol} / \mathrm{L}$ ABTS and $2.45 \mathrm{mmol} / \mathrm{L}$ potassium persulfate after incubation at room temperature for $16 \mathrm{~h}$ in the dark. The ABTS ${ }^{+}$radical solution was diluted with ethanol to an absorbance of $0.700 \pm 0.02$ at $734 \mathrm{~nm}$. $6 \mathrm{mg}$ of each extract was added to react with $2 \mathrm{~mL}$ of ABTS solution. The mixture was stored in the dark for $6 \mathrm{~min}$ and the absorbance at $734 \mathrm{~nm}$ was recorded using an Evolution 201 UV-vis Spectrophotometer (ThermoFisher, Waltham, MA). Ethanol was used as the control. Each measurement was conducted in duplicate. The scavenging of free radical was calculated according to the Eq. (1):

ABTS Scavenging activity $(\%)=$

$$
\frac{\text { Absorbance of control - Absorbance of sample }}{\text { Absorbance of control }}
$$

\subsection{Statistical analysis}

Design Expert software 10.0.6 was used for regression and graphical analysis of the data. A quartic polynomial equation that correlates the response (astaxanthin concentration, $\mu \mathrm{g} / \mathrm{g}$ oil) as a function of the independent variables and their interaction was developed. Analysis of variance (ANOVA) was used to determine the significance of the model through regression and mean square of residue error. The coefficient of determination $\left(R_{2}\right)$ was used to assess the quality of the 


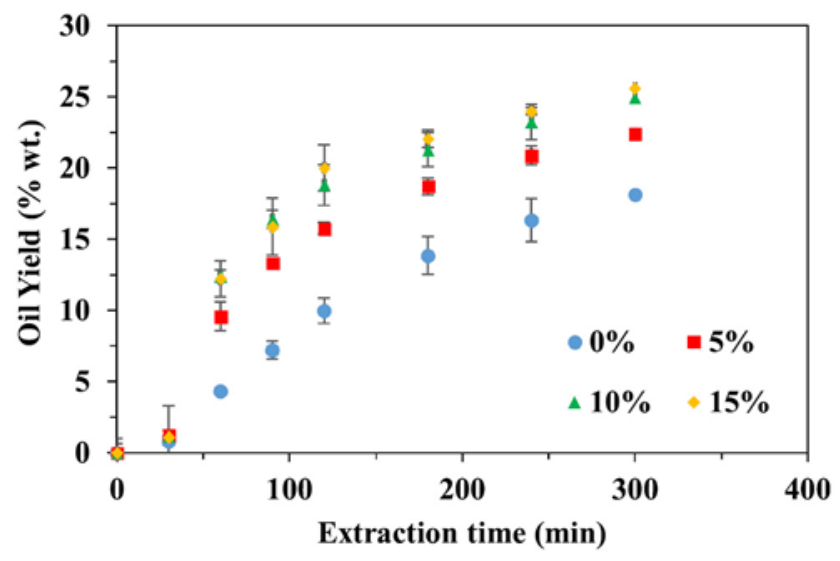

Fig. 1. Ethanol-modified $\mathrm{SC}-\mathrm{CO}_{2}$ extraction curves of camelina seed oil at $30 \mathrm{MPa}$ and $50{ }^{\circ} \mathrm{C}$ at varying ethanol concentrations; $\mathrm{n}=2$.

developed model. Analysis of the data to determine the statistical differences was performed by ANOVA and least-squares difference (LSD) using the SAS (version 9.4, SAS Institute Inc., Cary, NC, USA) at 95\% confidence interval.

\section{Results and discussion}

Preliminary studies were performed to observe the effect of ethanol concentration on the astaxanthin extraction and to determine the range of ethanol concentrations to be used in the RSM design, because ethanol-modified SC- $\mathrm{CO}_{2}$ extraction of astaxanthin was not performed on an oilseed before. Total oil yield increased with increasing ethanol content in the $\mathrm{SC}-\mathrm{CO}_{2}$ (Fig. 1). The highest oil yield of $25.6 \%$ was obtained at $15 \%$ ethanol concentration, whereas oil yield was only $18.1 \%$ with pure SC- $\mathrm{CO}_{2}$. Moreover, ethanol addition into $\mathrm{SC}-\mathrm{CO}_{2}$ increased the rate of the extraction, which is observed from the slope of the extraction lines in the first 120 min of the extraction (linear region) [20]. Astaxanthin content of the seed was $200 \mu \mathrm{g} / \mathrm{g}$ seed, including both free and esterified astaxanthin. Preliminary studies revealed that the astaxanthin content of the oils increased with increasing ethanol concentration (Fig. 2). Astaxanthin content of the oil extracted with pure SC- $\mathrm{CO}_{2}$ was $190 \mu \mathrm{g} / \mathrm{g}$ oil, whereas it was 304 $\mu \mathrm{g} / \mathrm{g}$ oil for the oil extracted with $15 \%$ ethanol in $\mathrm{SC}^{-\mathrm{CO}_{2}}$. In a study where astaxanthin was extracted from redspotted shrimp waste using $\mathrm{SC}-\mathrm{CO}_{2}$, the highest yield (2.3\% dry wt.) was obtained at $30 \mathrm{MPa}$ 


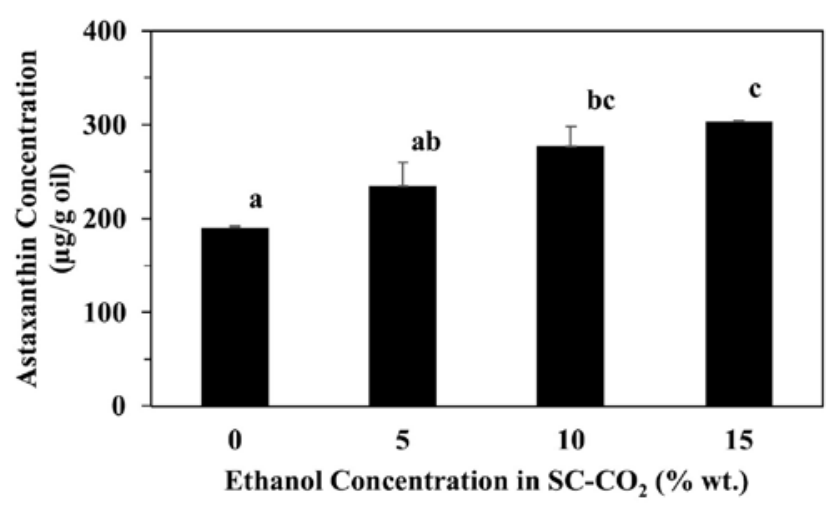

Fig. 2. Effect of the ethanol concentration in the $\mathrm{SC}-\mathrm{CO}_{2}$ on the astaxanthin concentration of the extracted oils obtained at $30 \mathrm{MPa}$ and $50{ }^{\circ} \mathrm{C}$. Different lowercase letters are significantly different for each extraction conditions $(p<0.05) ; n=2$.

and $50{ }^{\circ} \mathrm{C}$ [14]. Camargo et al. [2] reported that the astaxanthin concentration increased from 26 to $35 \mu \mathrm{g} / \mathrm{g}$ dry residue when $\mathrm{SC}-\mathrm{CO}_{2}$ was modified with $15 \%$ ethanol at $30 \mathrm{MPa}$ and $50^{\circ} \mathrm{C} . \mathrm{SC}-\mathrm{CO}_{2}$ is nonpolar; therefore, it cannot extract polar compounds and has limited capacity to extract slightly polar compounds. Ethanol increases the polarity of $\mathrm{SC}_{-} \mathrm{CO}_{2}$; therefore, increases the solubility of the astaxanthin in the ethanol-modified $\mathrm{SC}-\mathrm{CO}_{2}$ due to the slightly polar structure of astaxanthin. In addition, the SC- $\mathrm{CO}_{2}$-expanded ethanol helps to swell the pores of the seeds, which in turn improves the interaction of the solvent with the inner parts of the seed matrix. In a study by Lopez et al. [21], maximum astaxanthin yield was obtained with $15 \%$ ethanol, whereas, any further increase in the ethanol amount in the $\mathrm{SC}-\mathrm{CO}_{2}$ caused a considerable decrease in the astaxanthin yield. Effect of ethanol content of the $\mathrm{SC}-\mathrm{CO}_{2}$ depends on the matrix, polarity of the target compound, extraction pressure and temperature; therefore, optimization of the extraction conditions is required for each case.

\subsection{Model fitting}

Multiple regression was used to determine the effect of pressure, temperature and ethanol concentration on the $\mathrm{SC}-\mathrm{CO}_{2}$ extraction of astaxanthin from camelina seed from the 20 runs that were generated by the RSM (Table 2). Table 3 shows the statistical analysis of the quartic polynomial model based on ANOVA. After examining the lack of 
Table 2. Experimental variables $\left(X_{1}\right.$, pressure; $X_{2}$, temperature; $X_{3^{\prime}}$ ethanol concentration) and responses.

\begin{tabular}{lrrrrr} 
Run & $X_{1}$ & $X_{2}$ & $X_{3}$ & \multicolumn{2}{c}{ Astaxanthin concentration $(\mu \mathrm{g} / \mathrm{g}$ oil) } \\
\cline { 5 - 6 } & & & & Actual & Predicted \\
\hline 1 & -1 & +1 & -1 & 274 & 274 \\
2 & 0 & 0 & 0 & 305 & 298 \\
3 & -1 & -1 & -1 & 261 & 262 \\
4 & -1 & +1 & +1 & 283 & 283 \\
5 & 0 & 0 & 0 & 299 & 298 \\
6 & +1 & -1 & +1 & 364 & 364 \\
7 & -1.68 & 0 & 0 & 287 & 287 \\
8 & +1 & +1 & +1 & 276 & 276 \\
9 & 0 & -1.68 & 0 & 342 & 215 \\
10 & 0 & 0 & -1.68 & 208 & 298 \\
11 & 0 & 0 & 0 & 298 & 328 \\
12 & +1 & +1 & -1 & 328 & 396 \\
13 & +1.68 & 0 & 0 & 396 & 298 \\
14 & 0 & 0 & 0 & 310 & 270 \\
15 & -1 & -1 & +1 & 269 & 381 \\
16 & 0 & 0 & +1.68 & 375 & 270 \\
17 & 0 & +1.68 & 0 & 360 & 298 \\
18 & +1 & -1 & -1 & 270 & 298 \\
19 & 0 & 0 & 0 & 300 & \\
20 & 0 & 0 & 0 & &
\end{tabular}

fit, a quartic polynomial model was found to be adequate to explain the relationship between the astaxanthin yield and the extraction parameters. Backward-elimination was applied to refine the model by eliminating the insignificant terms. Model P-value $<0.0001$, an insignificant lack of fit ( $P$-value $=0.2351)$ and a higher coefficient of determination $\left(R^{2}=0.989\right)$ confirmed the suitability of the model to explain the relationship within the range of variables studied.

Regression coefficients were determined to predict the polynomial model for astaxanthin concentration and Eq. (2), expressed in coded variables, was obtained:

$$
\begin{aligned}
Y= & -20175.12+1161.47 X_{1}+925.47 X_{2}-111.28 X_{3}-52.32 X_{1} X_{2} \\
& +5.61 X_{1} X_{3}+0.60 X_{2} X_{3}-16.28 X_{1}^{2}-9.50 X_{2}^{2}-0.02 X_{1} X_{2} X_{3} \\
& +0.73 X_{1}^{2} X_{2}-0.06 X_{1}^{2} X_{3}+0.53 X_{1} X_{2}^{2}-0.007 X_{1}^{2} X_{2}^{2}
\end{aligned}
$$

where $X_{1}$ is pressure, $X_{2}$ is temperature, $X_{3}$ is ethanol concentration. The coefficients in front of every term $\left(X_{1}, X_{2}\right.$, and $\left.X_{3}\right)$ illustrate the effect of 
Table 3. ANOVA for the fitted quartic polynomial model for optimization of extraction conditions.

\begin{tabular}{|c|c|c|c|c|c|c|}
\hline Source & $\begin{array}{l}\text { Sum of } \\
\text { squares }\end{array}$ & $\begin{array}{r}\text { Degrees of } \\
\text { freedom }\end{array}$ & $\begin{array}{r}\text { Mean of } \\
\text { square }\end{array}$ & F-value & Prob $>F$ & Significance \\
\hline Model & 38016.86 & 13 & 2924.37 & 42.99 & $<0.0001$ & $* * *$ \\
\hline$X_{1}$ & 5955.77 & 1 & 5955.77 & 87.55 & $<0.0001$ & $* * *$ \\
\hline$x_{2}$ & 177.47 & 1 & 177.47 & 2.61 & 0.1574 & n.s. \\
\hline$x_{3}^{2}$ & 13804.57 & 1 & 13804.57 & 202.92 & $<0.0001$ & $* * *$ \\
\hline$x_{1}^{3} x_{2}$ & 388.37 & 1 & 388.37 & 5.71 & 0.0541 & n.s. \\
\hline$x_{1} x_{3}^{2}$ & 76.76 & 1 & 76.76 & 1.13 & 0.3290 & n.s. \\
\hline$x_{2} x_{3}^{3}$ & 2606.42 & 1 & 2606.42 & 38.31 & 0.0008 & $* * *$ \\
\hline$x_{1}^{2}$ & 3067.75 & 1 & 3067.75 & 45.10 & 0.0005 & $* * *$ \\
\hline$x_{2}^{2}$ & 4509.25 & 1 & 4509.25 & 66.29 & 0.0002 & $* * *$ \\
\hline$x_{1}^{2} x_{2} x_{3}$ & 2766.19 & 1 & 2766.19 & 40.66 & 0.0007 & $* * *$ \\
\hline $\mathrm{X}_{1}^{2} \mathrm{X}_{2}$ & 118.24 & 1 & 118.24 & 1.74 & 0.2355 & n.s. \\
\hline $\mathrm{X}_{1}^{2} \mathrm{X}_{3}^{2}$ & 5848.17 & 1 & 5848.17 & 85.97 & $<0.0001$ & $* * *$ \\
\hline$X_{1} X_{2}^{2}$ & 613.73 & 1 & 613.73 & 9.02 & 0.0239 & n.s. \\
\hline $\mathrm{X}_{1}{ }^{2} \mathrm{X}_{2}^{2}$ & 6594.35 & 1 & 6594.35 & 96.94 & $<0.0001$ & $* * *$ \\
\hline Lack of Fit & 108.97 & 1 & 108.97 & 1.82 & 0.2351 & n.s. \\
\hline Pure Error & 299.20 & 5 & 59.84 & & & \\
\hline Cor Total & 38425.03 & 19 & & & & \\
\hline
\end{tabular}

$\mathrm{CV}=2.71 \%, \mathrm{R}^{2}=0.9894$

*** $\mathrm{P}<0.001$; n.s., not significant.

a factor and the interaction among the factors, respectively. The positive sign in front of the terms indicates a synergistic effect, while the negative sign indicates an antagonistic effect. In the fitting model for this response variable, the pressure $(p<0.001)$ and ethanol concentration ( $p<0.001)$ affected the astaxanthin concentration linearly. Besides, an interaction of temperature and co-solvent was found.

\subsection{Effect of extraction parameters on the astaxanthin yield}

Fig. 3 presents the effects of extraction parameters on the astaxanthin concentration at $-1,0$, and +1 levels of the three variables. Unlike quadratic or cubic polynomial model, the RSM plots of the quartic model were complex. At lower pressure ( -1 level), ethanol concentration and temperature did not have a significant effect on the astaxanthin concentration (Fig. 3a). At moderate pressures (0 level), increasing ethanol concentration increased the astaxanthin yield at lower temperatures. At higher pressure (+1 level), increasing ethanol concentration at lower temperatures increased the astaxanthin yield; however, 
(a)

$$
\text { Pressure }=-1
$$

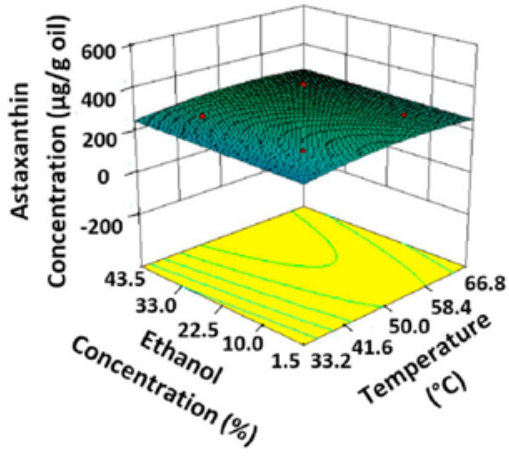

(b)

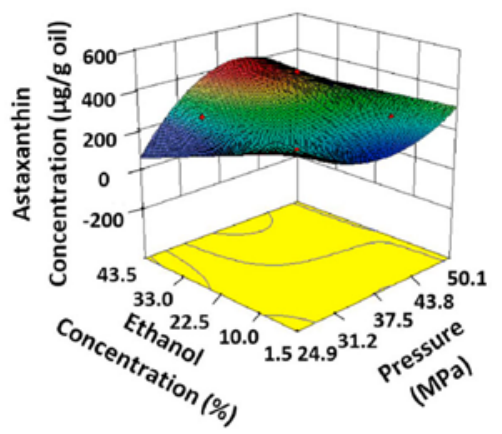

(c)

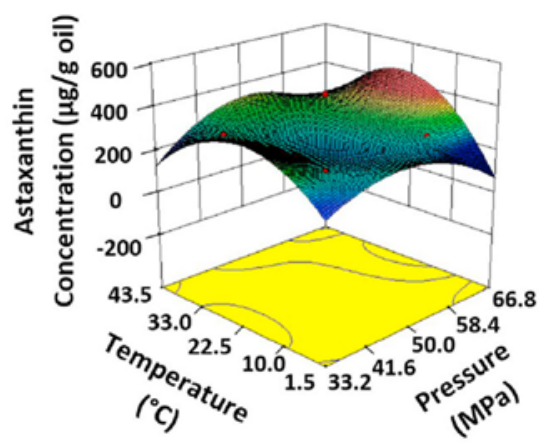

Pressure $=0$

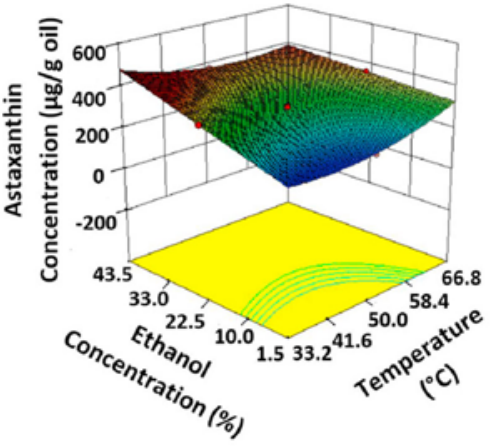

Temperature $=0$

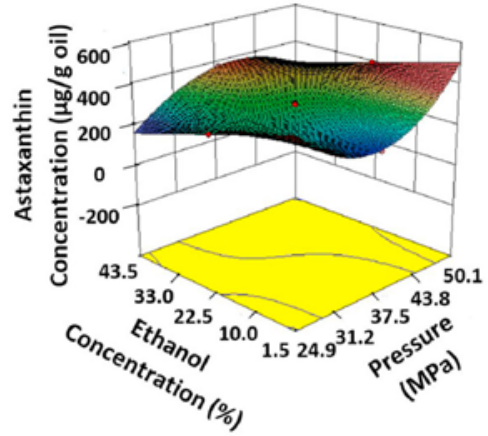

Ethanol $=0$

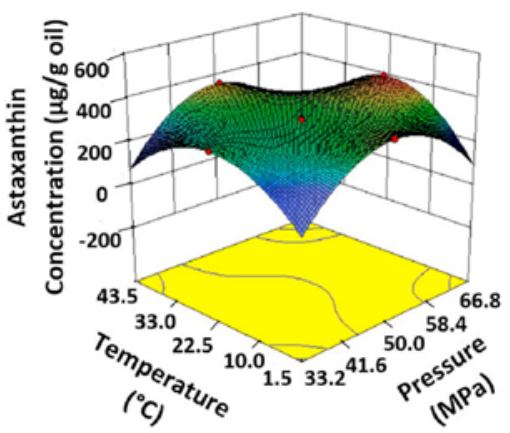

Pressure $=+1$

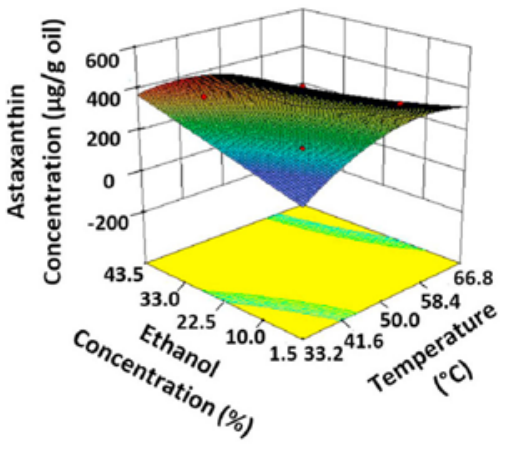

Temperature $=+1$

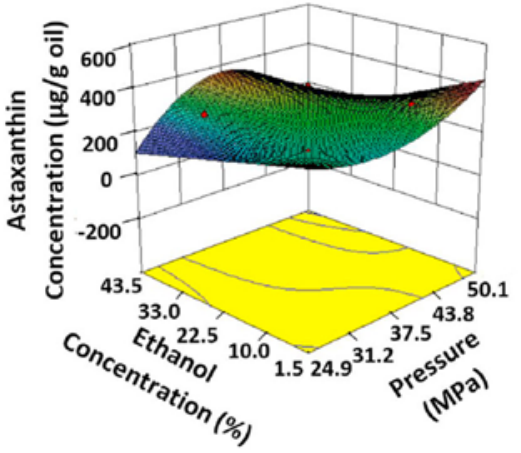

Ethanol $=+1$

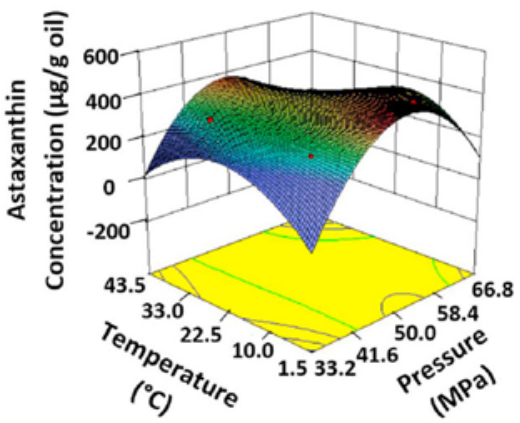

Fig. 3. Response surface plots of astaxanthin concentration at $-1,0$, and +1 levels of the independent variables. 
increasing ethanol concentration resulted in lower astaxanthin yields at higher temperatures. Effect of ethanol concentration and pressure on the astaxanthin yield at all temperature levels were similar. Regardless of the temperature level, at high ethanol concentration level, moderate pressure resulted in the highest astaxanthin concentration, whereas moderate pressure led to the lowest astaxanthin concentration when ethanol concentration was low. At all ethanol levels, moderate pressures yielded higher astaxanthin at all temperatures. However, at lower and higher pressures, astaxanthin yield was lower at lower and higher temperatures at all ethanol levels. The temperature had two opposing effects; the density of $\mathrm{CO}_{2}$ decreased with increasing temperature, which resulted in a reduced solvent power, on the other hand, increasing temperature led to an increase in the solute vapor pressure which affected the extraction positively. Furthermore, the temperature could affect the interaction between the solute and co-solvent molecules like hydrogen bond.

Extraction conditions were optimized to obtain the highest astaxanthin concentration using the RSM-developed model. The optimal extraction conditions were $41.6 \mathrm{MPa}, 36.6^{\circ} \mathrm{C}$ with $42.0 \%$ ethanol $(\mathrm{w} / \mathrm{w})$ at $1 \mathrm{~L} / \mathrm{min} \mathrm{CO}_{2}$ flow rate (measured at ambient conditions). The predicted optimum conditions were verified by three additional independent extractions at those optimum conditions. Optimum predicted astaxanthin concentration was $437 \mu \mathrm{g} / \mathrm{g}$ oil, while the oil yield was $28.3 \%$. The actual astaxanthin concentration was $421 \pm 14 \mu \mathrm{g} / \mathrm{g}$ oil, while the oil yield was $29 \pm 2 \%$. These results indicated that the experimental values were in good agreement with the predicted one.

Once the optimum extraction conditions were obtained, an extraction curve of the camelina seed oil was generated (Fig. 4) to investigate the effect of extraction time. In the experimental design, extraction time was limited to 180 min to avoid long extraction times during optimization. However, it was found that an extraction time of 120 min at the optimized conditions is enough for the maximum recovery of the astaxanthin. It was found that the oil extracted in the first one hour of the extraction has the highest astaxanthin concentration, meaning astaxanthin was extracted at a higher rate compared to camelina seed oil. This information is useful to obtain high purity products and to lower the processing costs with shorter extraction times. 


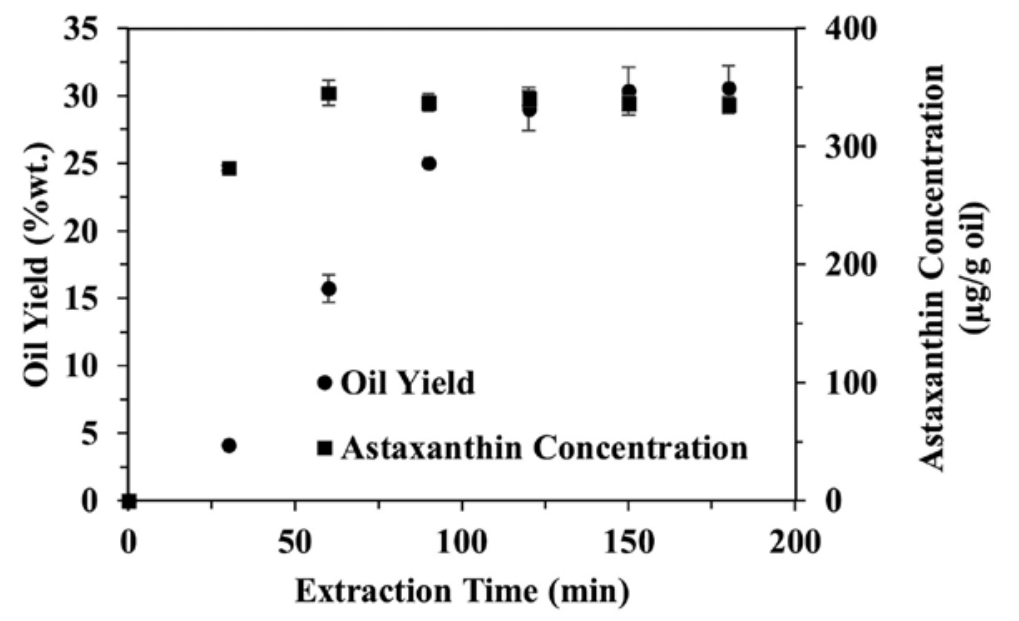

Fig. 4. Experimental extraction curves for oil yield and astaxanthin concentration at RSM-optimized conditions (41.6 MPa pressure, $36.6^{\circ} \mathrm{C}$ temperature, and $42.0 \%$ ethanol concentration, $w / w) ; n=2$.

\subsection{Comparison with other extraction methods}

Fig. 5 presents the comparison of the optimized ethanol-modified $\mathrm{SC}-\mathrm{CO}_{2}$ extraction $\left(\mathrm{SC}-\mathrm{CO}_{2, \text { opt }}\right)$ with conventional hexane extraction and accelerated solvent extraction using hexane and ethanol as solvents. There was no significant difference between the oil yield and

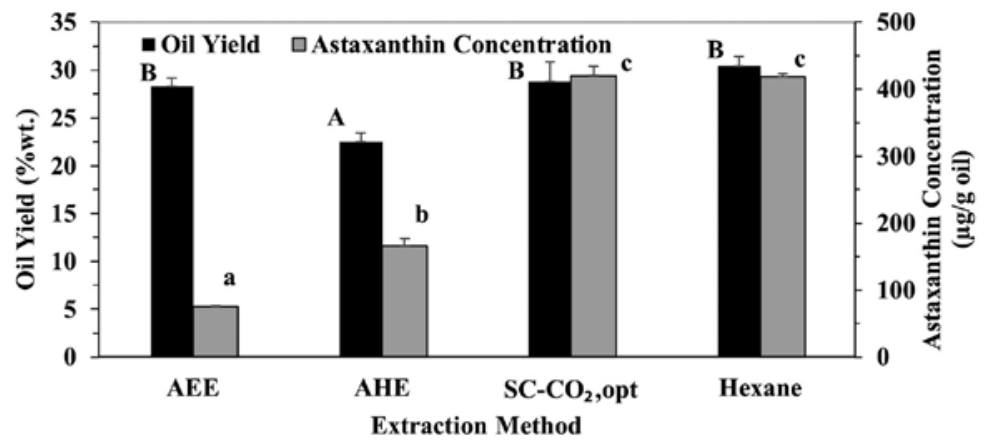

Fig. 5. Oil yield (black) and astaxanthin concentration (gray) obtained by $\mathrm{SCCO}_{2}$, ${ }_{\text {opt' }}$ ASE and Hexane (soxhlet) extraction. $\mathrm{SC}^{-} \mathrm{CO}_{2, \text { opt }}$ : Optimized $\mathrm{SC}-\mathrm{CO}_{2}$ extraction; AEE: Accelerated ethanol extraction; AHE: Accelerated hexane extraction. Different capital letters mean significant differences $(p<0.05)$ of the oil yield obtained from different extraction methods. Different lowercase letters mean significant differences $(p<0.05)$ of the astaxanthin concentration obtained from different extraction methods; $\mathrm{n}=2$. 
the astaxanthin concentration in the oils extracted with $\mathrm{SC}-\mathrm{CO}_{2, \text { opt }}$ and hexane. Astaxanthin concentration of the oil extracted with $\mathrm{SC}-\mathrm{CO}_{2, \text { opt }}$ was $421 \mu \mathrm{g} / \mathrm{g}$ oil, whereas it was $418 \mu \mathrm{g} / \mathrm{g}$ oil in the hexane-extracted one. The lowest oil yield (23\%) was obtained with accelerated hexane extraction (AHE), whereas the lowest astaxanthin concentration (75 $\mu \mathrm{g} / \mathrm{g}$ oil) was obtained with accelerated ethanol extraction (AEE). For $\mathrm{SCCO}_{2 \text {, opt' }}$ the ethanol consumption was $166 \mathrm{~mL}$, whereas it was 250 $\mathrm{mL}$ for the hexane (Soxhlet) extraction. ASE required approximately $50 \mathrm{~mL}$ solvent (ethanol or hexane), which was much less than hexane and $\mathrm{SCCO}_{2, \text { opt }}$ extractions. Lower solvent consumption is desired due to processing costs related to solvent storage, pumping, and separation. Although ASE required a shorter extraction time and consumed less solvent, the astaxanthin concentration was very low compared to $\mathrm{SC}-\mathrm{CO}_{2, \text { opt }}$ and hexane extraction methods. The lowest astaxanthin yield with AEE was due to high polarity of ethanol. Ethanol extracts polar compounds in the seed such as phospholipids and sugars but cannot extract slightly polar astaxanthin efficiently. A higher oil yield by $A E E$ compared to $A H E$, but a lower $\beta$-carotene concentration in the oil was previously reported by Eller et al. [11]. Compared to the hexane extraction, a shorter extraction time of $\mathrm{SC}-\mathrm{CO}_{2, \text { opt }}$ allowed us to extract more astaxanthin, although two values were not significantly different. Reyes et al. [22] reported astaxanthin extraction recoveries from Haematococcus pluvialis up to $82.3 \%$ using ethanol-modified $\mathrm{SC}-\mathrm{CO}_{2}$.

High ethanol concentrations in the optimized conditions suggested that better yields are obtained when a $\mathrm{CO}_{2}$-expanded ethanol was formed. Actually, the mechanism of extraction in a $\mathrm{CO}_{2}$-expanded ethanol may be different than ethanol-modified $\mathrm{SC}-\mathrm{CO}_{2}$ extraction where pressure and temperature play the critical role by changing the solubility of astaxanthin in the supercritical phase, whereas when the ethanol content in the $\mathrm{SC}-\mathrm{CO}_{2}$ approaches $50 \%$, the mixture behaves like a pressurized liquid [23]. However, the low astaxanthin yields from AEE showed that the extraction mechanism of the AEE and the $\mathrm{CO}_{2}$ - expanded ethanol extraction is different. Both higher pressures and high ethanol contents at the optimized ethanol-modified $\mathrm{SC}-\mathrm{CO}_{2}$ extraction played the role by improving the mass transfer by higher pressures and improving polarity by the presence of ethanol. In must be noted that, in this study, the matrix contained high amount of oil which acted 
as co-solvent; therefore, the extraction mechanism was different than that of extracted from high water-content marine animals. Previously, Krichnavaruk et al. [24] used soybean oil, olive oil and ethanol as cosolvent to extract astaxanthin from microalgae Haematococcus pluvialis. At the same extraction conditions, olive oil gave a comparable result to that with ethanol, however, soybean oil gave the lowest extraction efficiency. Those results suggested that the properties of the oil (e.g., fatty acid composition and viscosity) and the solubility of the oil in the $\mathrm{SC}-\mathrm{CO}_{2}$ could affect the astaxanthin extraction efficiency. In another study, transgenic maize was extracted with ethanol in combination with added commercial maize oil, and it was found that this combination was as effective as tetrahydrofuran and chloroform [5]. In the study of transgenic maize [5], the astaxanthin concentration of the final oil was $1 \mu \mathrm{g} / \mathrm{g}$ oil, which was considerably lower than the astaxanthin concentration obtained in this study.

In general, the polarity of the solvent used in the extraction should be the same as or similar with that of the target compounds, however, in some cases, using the mixture of polar and non-polar solvents may get higher recoveries [25]. For example, Yu et al. [26] used a mixture of hexane and methanol as solvents to extract amitraz and 2,4- dimethylaniline (2,4- DMA) from animal tissues. Because amitraz is less polar than 2,4- DMA, higher ratio of methanol in the mixture should result in a higher recovery for 2,4- DMA but not for amitraz. However, the highest recovery for both amitraz and 2,4- DMA was obtained when hexane/ methanol ratio was at a ratio of 1:9 (v/v) [26]. Solvents used in the extraction not only act as the carrier of target compound, but also have other functionalities. For example, the solvent can also swell the pores of the seeds or other materials. Thus, using the mixture of hexane and ethanol of ASE might result in higher recovery for oil, astaxanthin or both of them. However, mixing ethanol with hexane can be a concern for the manufacturers as the use of hexane cannot generate a product that complies with clean labeling.

3.4. Tocopherol content of the extracts obtained from different extraction methods

Tocopherols are important minor lipid components in camelina seed, and are best known for their antioxidant activities. Table $\mathbf{4}$ presents 
Table 4. Effect of extraction method on the tocopherol composition of the oils.

\begin{tabular}{lcccc} 
& \multicolumn{4}{c}{ Tocopherol content (mg/kg oil) } \\
\cline { 2 - 5 } Extraction method & $\delta$ & $\gamma$ and $\beta$ & $\alpha$ & Total \\
\hline AEE & $20 \pm 0^{\mathrm{c}}$ & $610 \pm 8^{\mathrm{a}}$ & $5 \pm 0^{\mathrm{a}}$ & $633 \pm 8^{\mathrm{a}}$ \\
$\mathrm{AHE}$ & $17 \pm 1^{\mathrm{a}}$ & $621 \pm 5^{\mathrm{a}}$ & $12 \pm 1^{\mathrm{c}}$ & $650 \pm 6^{\mathrm{a}}$ \\
$\mathrm{SC}-\mathrm{CO}_{2, \text { opt }}$ & $17 \pm 1^{\mathrm{ab}}$ & $613 \pm 13^{\mathrm{a}}$ & $9 \pm 0^{\mathrm{b}}$ & $640 \pm 13^{\mathrm{a}}$ \\
Hexane & $18 \pm 1^{\mathrm{bc}}$ & $732 \pm 12^{\mathrm{b}}$ & $13 \pm 0^{\mathrm{c}}$ & $763 \pm 11^{\mathrm{b}}$ \\
\hline
\end{tabular}

Values followed by the different letters indicate significant difference $(p<0.05) ; n=2$.

AEE: Accelerated ethanol extraction; AHE: Accelerated hexane extraction; $\mathrm{SC}-\mathrm{CO}_{2, \mathrm{opt}}$ : Optimized ethanol-modified SC-CO2 extraction.

the tocopherol composition of the oils obtained by four different extraction methods. The oils extracted with hexane contained the highest amount of tocopherols ( $763 \mathrm{mg} / \mathrm{kg}$ oil). Tocopherol content of the oils extracted with $\mathrm{AEE}, \mathrm{AHE}$, and $\mathrm{SC}-\mathrm{CO}_{2, \text { opt }}$ ranged between 633 and $650 \mathrm{mg} / \mathrm{kg}$ oil, and there was no significant difference among them $(p>0.05) . \gamma$ - and $\beta$ - Tocopherols were the dominant tocopherols in all oils and their level ranged from $610 \mathrm{mg} / \mathrm{kg}$ oil (AEE) to 732 $\mathrm{mg} / \mathrm{kg}$ oil (hexane). Low concentration of $\delta$-tocopherol (17-20 mg/ $\mathrm{kg}$ oil) followed by $\alpha$-tocopherol ( $5-13 \mathrm{mg} / \mathrm{kg}$ oil) was detected in all samples. No significant difference was observed between the tocopherol contents of the oils extracted by $\mathrm{AEE}$, $\mathrm{AHE}$, and $\mathrm{SC}-\mathrm{CO}_{2, \mathrm{opt}}$. Tocopherols are nonpolar compounds and they show good solubility both in hexane and pure $\mathrm{SC}-\mathrm{CO}_{2}$; therefore, increasing the polarity of $\mathrm{SC}-\mathrm{CO}_{2}$ by ethanol decreased the extraction of tocopherols. Reports on the tocopherol content of camelina seed oil are scarce. Previously, tocopherol content of hexane- and $\mathrm{SC}-\mathrm{CO}_{2}-\mathrm{ex}-$ tracted non-engineered camelina seed oil was reported as 653 and $766 \mathrm{mg} / \mathrm{kg}$, respectively [16]. It was shown that modification of SC$\mathrm{CO}_{2}$ with ethanol up to $10 \%$ ethanol at $35 / 45 \mathrm{MPa}$ and $50 / 70{ }^{\circ} \mathrm{C}$ did not cause a significant difference in the extraction of tocopherols, but in this study it was shown that a drastic increase in the ethanol content of the SC- $\mathrm{CO}_{2}$ decreases the extraction of tocopherols significantly compared to pure $\mathrm{SC}-\mathrm{CO}_{2}$. 
Table 5. Effect of extraction method on the ABTS radical scavenging activity of the oils.

\begin{tabular}{lc} 
Extraction method & ABTS scavenging activity (\%) \\
\hline AEE & $32 \pm 1^{\text {a }}$ \\
AHE & $39 \pm 1^{\mathrm{b}}$ \\
$\mathrm{SC}-\mathrm{CO}_{2, \text { opt }}$ & $65 \pm 1^{\mathrm{d}}$ \\
Hexane & $48 \pm 2^{\mathrm{c}}$ \\
\hline
\end{tabular}

Values followed by the different letters indicate significant difference $(p<0.05) ; n=2$. AEE: Accelerated ethanol extraction; AHE: Accelerated hexane extraction; $\mathrm{SC}-\mathrm{CO}_{2, \text { opt }}$ : Optimized ethanol-modified $\mathrm{SC}-\mathrm{CO}_{2}$ extraction.

3.5. Antioxidant activity of the extracts obtained from different extraction methods

The ABTS radical scavenging activity of engineered camelina seed oils obtained from four extraction methods is shown in Table 5. The oil extracted from $\mathrm{SC}-\mathrm{CO}_{2, \text { opt }}$ showed the highest scavenging activity (65\%), followed by hexane (48\%), and AHE (39\%). The lowest scavenging activity was obtained from AEE (32\%). Results have shown that the ABTS scavenging activity increased with increasing astaxanthin content of the oils (Fig. 5). Tocopherols are natural antioxidants; however, it was found that astaxanthin content was the major factor determining the antioxidant activity of the oils. Even though the hexane-extracted oil had the highest tocopherol content, it did not have the highest antioxidant activity.

Previously, Reyes et al. [22] stated that the antioxidant activity increased as the astaxanthin concentration in the extract from Haematococcus pluvialis increased regardless of the extraction method. However, Jaime et al. [27] reported that the carotenoids in Haematococcus pluvialis extracted by AEE had higher antioxidant activity than those by AHE. The extraction condition and target compound could affect the selection of the appropriate solvent, resulting in different results. The oil extracted by $\mathrm{SC}-\mathrm{CO}_{2, \text { opt }}$ had higher antioxidant activity compared to that obtained by hexane extraction, even though their astaxanthin concentration in the oils were similar, showing the possible effect of other polar minor lipid compounds with antioxidant properties. Shao et al. [28] compared the antioxidant activity of essential oils extracted from Anoectochilus roxburghii by hexane extraction and 
$\mathrm{SC}-\mathrm{CO}_{2}$ extraction and also reported that the oils extracted by $\mathrm{SC}-\mathrm{CO}_{2}$ showed higher antioxidant activity than those by hexane.

It should be noted that the material being investigated plays an important role in the antioxidant properties. The ABTS method measured the total antioxidant capacity of the extract, the specific chemical compositions of the extract could affect the antioxidant activity. Tocopherols are natural compounds that can have a synergistic effect on the antioxidant activity of the oils. Kang et al. [29] reported that the highest antioxidant activity of paprika leave was achieved by the highest amount of lutein and $\gamma$ - tocopherol in the extract. Our results suggested that tocopherols did not have a significant contribution to the antioxidant activity of the samples because the antioxidant activity of astaxanthin is much higher than that of tocopherols.

\section{Conclusions}

Engineered camelina seed was found to be a promising alternative source for astaxanthin. Ethanol-modified $\mathrm{SC}-\mathrm{CO}_{2}$ can be successfully used as a green extraction technique to extract astaxanthin. RSM was useful in optimizing the ethanol-modified $\mathrm{SC}-\mathrm{CO}_{2}$ extraction of astaxanthin from camelina oil seed. Ethanol-modified $\mathrm{SC}-\mathrm{CO}_{2}$ was more effective than $\mathrm{AEE}$ and $\mathrm{AHE}$, and as effective as hexane to extract astaxanthin from camelina seed. Compared to hexane extraction, ethanol-modified $\mathrm{SC}-\mathrm{CO}_{2}$ extraction can provide protection to astaxanthin against oxidation and also eliminates the hazardous solvents from processing.

Acknowledgments - Authors thank Anji Reddy Konda for the assistance in tocopherol analysis, and Dr. Mark Wilkins from the Industrial Agricultural Products Center for giving us access to the accelerated solvent extraction system.

\section{References}

[1] S. Dong, Y. Huang, R. Zhang, S. Wang, Y. Liu, Four different methods comparison for extraction of astaxanthin from green alga Haematococcus pluvialis, Sci. World J. 2014 (2014). 
[2] A.P. Sanchez-Camargo, M.A.A. Meireles, A.L.K. Ferreira, E. Saito, F.A. Cabral, Extraction of $\omega-3$ fatty acids and astaxanthin from Brazilian redspotted shrimp waste using supercritical $\mathrm{CO} 2$ + ethanol mixtures, J. Supercrit. Fluids 61 (2012) 71-77.

[3] J.P. Yuan, J. Peng, K. Yin, J.H. Wang, Potential health-promoting effects of astaxanthin: a high-value carotenoid mostly from microalgae, Mol. Nutr. Food Res. 55 (2011) 150-165.

[4] P. Kittikaiwan, S. Powthongsook, P. Pavasant, A. Shotipruk, Encapsulation of Haematococcus pluvialis using chitosan for astaxanthin stability enhancement, Carbohydr. Polym. 70 (2007) 378-385.

[5] J. Breitenbach, M. Nogueira, G. Farre, C. Zhu, T. Capell, P. Christou, G. Fleck, U. Focken, P.D. Fraser, G. Sandmann, Engineered maize as a source of astaxanthin: processing and application as fish feed, Transgenic Res. 25 (2016) 785-793.

[6] J. Jayaraj, R. Devlin, Z. Punja, Metabolic engineering of novel ketocarotenoid production in carrot plants, Transgenic Res. 17 (2008) 489-501.

[7] J.C. Huang, Y.J. Zhong, J. Liu, G. Sandmann, F. Chen, Metabolic engineering of tomato for high-yield production of astaxanthin, Metab. Eng. 17 (2013) 59-67.

[8] R.Y. Khattab, M.A. Zeitoun, Quality evaluation of flaxseed oil obtained by different extraction techniques, LWT - Food Sci. Technol. 53 (2013) 338-345.

[9] A. Rai, B. Mohanty, R. Bhargava, Supercritical extraction of sunflower oil: a central composite design for extraction variables, Food Chem. 192 (2016) 647-659.

[10] A. Rai, B. Mohanty, R. Bhargava, Modeling and response surface analysis of supercritical extraction of watermelon seed oil using carbon dioxide, Sep. Purif. Technol. 141 (2015) 354-365.

[11] F.J. Eller, J.K. Moser, J.A. Kenar, S.L. Taylor, Extraction and analysis of tomato seed oil, J. Am. Oil Chem. Soc. 87 (2010) 755-762.

[12] L. Jaime, E. Vazquez, T. Fornari, M.C. Lopez-Hazas, M.R. Garcia-Risco, S. Santoyo, G. Reglero, Extraction of functional ingredients from spinach (Spinacia oleracea L.) using liquid solvent and supercritical CO2 extraction, J. Sci. Food Agric. 95 (2015) 722-729.

[13] S. Machmudah, A. Shotipruk, M. Goto, M. Sasaki, T. Hirose, Extraction of astaxanthin from Haematococcus pluvialis using supercritical $\mathrm{CO}_{2}$ and ethanol as entrainer, Ind. Eng. Chem. Res. 45 (2006) 3652-3657.

[14] A.P. Sanchez-Camargo, H.A. Martinez-Correa, L.C. Paviani, F.A. Cabral, Supercritical $\mathrm{CO}_{2}$ extraction of lipids and astaxanthin from Brazilian redspotted shrimp waste (Farfantepenaeus paulensis), J. Supercrit. Fluids 56 (2011) 164-173.

[15] S.A. Radzali, B.S. Baharin, R. Othman, M. Markom, R.A. Rahman, Cosolvent selection for supercritical fluid extraction of astaxanthin and other carotenoids from Penaeus monodon waste, J. Oleo Sci. 63 (2014) 769-777.

[16] H.D. Belayneh, R.L. Wehling, A.K. Reddy, E.B. Cahoon, O.N. Ciftci, Ethanolmodified supercritical carbon dioxide extraction of the bioactive lipid components of Camelina sativa seed, J. Am. Oil Chem. Soc. (2017) 1-11. 
[17] K. Zaghdoudi, S. Pontvianne, X. Framboisier, M. Achard, R. Kudaibergenova, M. Ayadi-Trabelsi, J. Kalthoum-cherif, R. Vanderesse, C. Frochot, Y. Guiavarc'h, Accelerated solvent extraction of carotenoids from: Tunisian kaki (Diospyros kaki L.), peach (Prunus persica L.) and apricot (Prunus armeniaca L.), Food Chem. 184 (2015) 131-139.

[18] P. Du, M. Jin, L. Yang, G. Chen, C. Zhang, F. Jin, H. Shao, M. Yang, X. Yang, Y. She, S. Wang, L. Zheng, J. Wang, Determination of astaxanthin in feeds using high performance liquid chromatography and an efficient extraction method, J. Liq. Chromatogr. Relat. Technol. 39 (2016) 35-43.

[19] H.D. Belayneh, R.L. Wehling, E. Cahoon, O.N. Ciftci, Extraction of omega-3-rich oil from Camelina sativa seed using supercritical carbon dioxide, J. Supercrit. Fluids 104 (2015) 153-159.

[20] O.N. Ciftci, J. Calderon, F. Temelli, Supercritical carbon dioxide extraction of corn distiller's dried grains with solubles: experiments and mathematical modeling, J. Agric. Food Chem. 60 (2012) 12482-12490.

[21] M. Lopez, L. Arce, J. Garrido, A. Rí os, M. Valcarcel, Selective extraction of astaxanthin from crustaceans by use of supercritical carbon dioxide, Talanta 64 (2004) 726-731.

[22] F.A. Reyes, J.A. Mendiola, E. Ibanez, J.M. del Valle, Astaxanthin extraction from Haematococcus pluvialis using $\mathrm{CO}_{2}$-expanded ethanol, J. Supercrit. Fluids 92 (2014) 75-83.

[23] M.T. Golmakani, J.A. Mendiola, K. Rezaei, E. Ibanez, Expanded ethanol with $\mathrm{CO}_{2}$ and pressurized ethyl lactate to obtain fractions enriched in $\gamma$-linolenic acid from Arthrospira platensis (Spirulina), J. Supercrit. Fluids 62 (2012) 109-115.

[24] S. Krichnavaruk, A. Shotipruk, M. Goto, P. Pavasant, Supercritical carbon dioxide extraction of astaxanthin from Haematococcus pluvialis with vegetable oils as cosolvent, Bioresour. Technol. 99 (2008) 5556-5560.

[25] H. Sun, X. Ge, Y. Lv, A. Wang, Application of accelerated solvent extraction in the analysis of organic contaminants, bioactive and nutritional compounds in food and feed, J. Chromatogr. A 1237 (2012) 1-23.

[26] H. Yu, Y. Tao, T. Le, D. Chen, A. Ishsan, Y. Liu, Y. Wang, Z. Yuan, Simultaneous determination of amitraz and its metabolite residue in food animal tissues by gas chromatography-electron capture detector and gas chromatographymass spectrometry with accelerated solvent extraction, J. Chromatogr. B 878 (2010) 1746-1752.

[27] L. Jaime, I. Rodriguez-Meizoso, A. Cifuentes, S. Santoyo, S. Suarez, E. Ibanez, F.J. Senorans, Pressurized liquids as an alternative process to antioxidant carotenoids' extraction from Haematococcus pluvialis microalgae, LWT Food Sci. Technol. 43 (2010) 105-112.

[28] Q. Shao, Y. Deng, H. Liu, A. Zhang, Y. Huang, G. Xu, M. Li, Essential oils extraction from Anoectochilus roxburghii using supercritical carbon dioxide and their antioxidant activity, Ind. Crops Prod. 60 (2014) 104-112.

[29] J.H. Kang, S. Kim, B. Moon, Optimization by response surface methodology of lutein recovery from paprika leaves using accelerated solvent extraction, Food Chem. 205 (2016) 140-145. 